\title{
Incorporação de ar em materiais cimentícios: uma nova abordagem para o desenvolvimento de argamassas de revestimento
}

\author{
Air-incorporation in cementitious materials: a new \\ approach for developing rendering mortars
}

\section{Roberto Cesar de Oliveira Romano Maria Alba Cincotto Rafael Giuliano Pileggi}

\section{Resumo

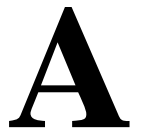

utilização de incorporadores de ar em argamassas de revestimento é comum no setor construtivo e estudada há muitos anos, seja na academia ou em centros privados de pesquisa. Por isso, uma gama muito ampla de informações obtidas com os inúmeros estudos são reportadas em literatura, na maioria dos casos ilustrando os efeitos da incorporação de ar, trabalhabilidade, espalhamento, módulo de elasticidade, aumento da permeabilidade ao ar, etc. No entanto, poucas informações são obtidas com relação às causas que resultam em tais efeitos, o que pode ser considerada a fonte das incertezas e empirismo durante o processo de desenvolvimento de tais composições cimentícias. Assim, neste trabalho é apresentada uma revisão sobre as variáveis que influenciam na incorporação de ar nos sistemas cimentícios, que aponta para o impacto da utilização do aditivo na água em presença de cimento (pasta) e na argamassa como um todo.

Palavras-chaves: Argamassa. Incorporador de ar. Cimento Portland.

Roberto Cesar de Oliveira
Romano
Universidade de São Paulo São Paulo - SP - Brasil

Maria Alba Cincotto Universidade de São Paulo São Paulo - SP - Brasil

Rafael Giuliano Pileggi Universidade de São Paulo São Paulo - SP - Brasil

Recebido em 13/09/16 Aceito em 14/08/17

\section{Abstract}

The use of air-entraining agents in rendering mortars has been studied for many years both at universities and private research centers. Hence, there is a wealth of information on this theme in the literature, mainly describing the EFFECTS of air-incorporation on workability, spreading, modulus of elasticity, air permeability increase, etc. However, very little information is available on the air-incorporation CAUSES which result in such effects, which may be considered the source of uncertainties and empiricism in the process of development of cementitious compositions. This study presents a review of the variables that may influence air-incorporation in cementitious systems, pointing to the impact of using air-entraining agent in water in the presence of cement particles (paste) and in the mortar.

Keywords: Mortar. Air-entraining agent. Portland cement. 


\section{Introdução}

O advento dos incorporadores de ar (AIA) e sua utilização em materiais cimentícios representaram um importante avanço tecnológico do setor de construção civil (DU; FOLLIARD, 2005), pois possibilita:

(a) melhorar a trabalhabilidade;

(b) melhorar a coesão dos sistemas;

(c) reduzir a tendência à exsudação;

(d) facilitar o espalhamento e o manuseio, e aumentar a produtividade;

(e) utilizar formas que suportem menores pressões;

(f) reduzir as cargas sobre as estruturas, a dimensão das fundações e o módulo de elasticidade;

(g) aumentar a resistência a ciclos de gelo-degelo; e

(h) reduzir o consumo de cimento nas composições.

No entanto, tal prática, apesar de ser muito utilizada em países onde o clima frio é predominante, não é trivial, visto que muitas variáveis podem influenciar na geração intencional de bolhas nas argamassas e concretos.

Por isso, muitos esforços vêm sendo realizados sobre o tema desde então: Powers $(1949,1954)$ desenvolveu um conceito para apresentar a disposição espacial das bolhas em concretos e a relação com a resistência a ciclos de gelo-degelo; Bruere (1955) discutiu os fatores que afetam a entrada de ar em pastas de cimento e sílica; Mielenz et al. (1958) discutiram em detalhes a origem e a evolução das bolhas de ar nas composições cimentícias; Powers (1968), apesar de não levar em consideração alguns aspectos químicos da formação das bolhas e dos aditivos, discutiu a influência de diversos fatores na geração de ar nos materiais cimentícios; Fagerlund (1990) propôs três mecanismos que podem servir para explicar a instabilidade das bolhas de ar nos concretos e argamassas no estado fresco; Zhang (1996) estudou o efeito de diferentes tipos de adições na geração de ar, estabilidade e tempo para colapsação das bolhas em materiais cimentícios usando vários tipos de aditivos incorporadores de ar; Alves (2002) estudou o impacto da incorporação de ar em argamassas de revestimento no estado fresco; Monte, Uemoto e Selmo (2003) avaliaram diversos tipos de aditivos incorporadores de ar para aplicação em argamassas de assentamento e revestimento; Romano et al. (2007a, 2007b, 2009, 2011a, 2011b, 2011c); e
Romano e Pileggi (2012) investigaram o efeito do tipo e teor de incorporador de ar, a interação com outros tipos de aditivos e o efeito do tempo de mistura e do tipo de equipamento nas propriedades de argamassas de revestimento.

Entretanto, apesar da nítida evolução nas pesquisas com relação ao tema, a maioria dos trabalhos deu ênfase aos efeitos práticos da presença do ar nas composições, sendo pouco explorados os mecanismos de formação e estabilização das bolhas. Temperatura, tempo de mistura, tipo de cimento, tipo e teor de aditivo ou adição mineral, quantidade de água para o amassamento, etc., são algumas dessas variáveis que, muitas vezes, dificultam a utilização desses materiais no setor construtivo.

Para se ter uma ideia, no site da Portland Cement Association há um levantamento, a partir de trabalhos publicados ou com base em pesquisas da própria associação, indicando os efeitos de vários tipos de materiais ou práticas em obra que influenciam no nível de ar de materiais cimentícios, conforme transcrito na Tabela 1.

Como pode ser visto, muitas são as variáveis que influenciam no teor de ar incorporado, por isso é de grande importância o correto entendimento dos fenômenos envolvidos na geração e na estabilidade das bolhas de ar nas composições, fato pouco abordado em trabalhos voltados para construção civil. Assim, a compreensão do que são os incorporadores de ar, como atuam na água e em presença de cimento, é primordial para entender os efeitos provocados quando são utilizados nas argamassas.

\section{Aditivos incorporadores de ar}

Os incorporadores de ar são espécies químicas que apresentam na mesma molécula uma extremidade hidrofóbica (apolar) e outra hidrofílica (polar), sendo conhecidos como compostos anfifílicos (SALAGER, 1992; ROMANO, 2005). A extremidade apolar é frequentemente uma cadeia hidrocarbônica, enquanto a extremidade polar pode ser iônica (catiônica ou aniônica), não iônica, ou anfótera.

Devido a tal peculiaridade, os incorporadores de ar mostram forte tendência de migrar para as interfaces, de forma a que o grupo polar permaneça em contato com a fase líquida, e o grupo apolar se encontre orientado para o ar, solvente orgânico ou partícula (SALAGER, 2002; ROMANO, 2005), originando propriedades físicas e químicas especiais com larga aplicação prática. 
Tabela 1 - Efeito do tipo de material ou práticas de produção em obra no teor de ar em materiais cimentícios

\begin{tabular}{|c|c|c|}
\hline Material / Prática (obra) & Alteração & Efeito no teor de ar \\
\hline \multirow{3}{*}{ Cimento } & Aumento do teor & $\downarrow$ \\
\hline & Aumento da finura & $\downarrow$ \\
\hline & Aumento do teor de álcalis & $\uparrow$ \\
\hline \multirow{4}{*}{ Adições minerais } & Cinza volante & $\downarrow \downarrow$ \\
\hline & Sílica ativa & $\downarrow \downarrow$ \\
\hline & Escória de alto forno & $\downarrow$ \\
\hline & Metacaulim & $\leftrightarrow$ \\
\hline \multirow[t]{2}{*}{ Agregados } & $\begin{array}{l}\text { Aumento da extensão } \\
\text { granulométrica }\end{array}$ & $\downarrow$ \\
\hline & Aumento de areia & $\uparrow$ \\
\hline \multirow{3}{*}{ Aditivos químicos } & Superplastificantes & $\bar{\uparrow}$ \\
\hline & Retardadores & $\uparrow$ \\
\hline & Aceleradores & $\leftrightarrow$ \\
\hline Água/cimento & Aumento & $\uparrow$ \\
\hline \multirow{3}{*}{ Abatimento } & $>150 \mathrm{~mm}$ & $\downarrow$ \\
\hline & Até $150 \mathrm{~mm}$ & $\uparrow$ \\
\hline & $<75 \mathrm{~mm}$ & $\downarrow$ \\
\hline \multirow{4}{*}{ Produção/Misturador } & Batelada & $\uparrow \downarrow$ \\
\hline & Misturador de alta capacidade & $\uparrow$ \\
\hline & Alta rotação & $\uparrow$ \\
\hline & Maior tempo de mistura & 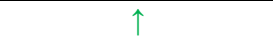 \\
\hline \multirow{2}{*}{ Transporte } & Longo tempo & $\downarrow$ \\
\hline & Remistura & $\uparrow$ \\
\hline \multirow{4}{*}{ Aplicação e acabamento } & Bombeamento & $\downarrow$ \\
\hline & Projeção & $\downarrow$ \\
\hline & Vibração & $\downarrow$ \\
\hline & Excesso de acabamento & $\downarrow$ \\
\hline
\end{tabular}

Do ponto de vista energético, pode-se dizer que a energia livre de uma molécula de incorporador de ar na superfície (ou interface) é inferior à energia da molécula solubilizada no interior da fase aquosa. Sendo assim, a transferência do interior do meio líquido para a superfície (adsorção) é espontânea, resultando na redução da tensão superficial (ou interfacial), responsável por inúmeros fenômenos de estabilização de interfaces (SALAGER, 1992).

Do ponto de vista comercial, tais aditivos classificam-se segundo sua aplicação, mas como um único aditivo pode ser utilizado para distintas funções é conveniente classificá-los de acordo com a estrutura de suas moléculas, mais exatamente conforme se dissociam em água.
No caso dos materiais aplicados em construção civil, os mais utilizados são os aditivos de caráter dissociativo aniônico, devido à melhor compatibilidade com o cimento e ao menor custo. Trata-se de aditivos com ânion anfifílico (polar) e cátion metálico ou de amônio. Os grupos polares mais comuns são carboxilatos, sulfatos, sulfonatos e fosfatos (HOLMBERG et al., 2002), categoria que representa quase $60 \%$ da produção de surfactantes (SALAGER; FERNANDES, 2004).

Os aditivos sulfonados e sulfatados representam aproximadamente a metade da produção de todos os incorporadores de ar (independentemente da classe de dissociação) e, com poucas exceções de menor importância, são fabricados por reações de sulfonação ou sulfatação de alquilbenzenos, 
alfaolefinas e álcoois com e sem o grupo óxido de etileno.

\section{Incorporação de ar em argamassas}

A incorporação de ar melhora a coesão das argamassas de revestimento, reduz a tendência à exsudação, melhora a plasticidade e possibilita reduzir a quantidade de água necessária para o amassamento, o que, possivelmente, diminui a retração plástica e por secagem (BENINGFIELD, 1988; ALVES, 2002).

Uma ilustração do efeito provocado pela utilização desse tipo de aditivo na argamassa fresca é mostrada na Figura 1, onde em (a) é apresentada uma foto de argamassa sem adição de AIA e em (b) uma foto da mesma argamassa aditivada com incorporador de ar.

Tais alterações são observadas porque a presença do aditivo afeta as características superficiais do líquido e porque as bolhas diminuem o atrito interno entre os grãos e afastam os agregados. O atrito somente ocorre quando dois corpos sólidos se tocam e suas superfícies deslizam uma sobre a outra. Assim, quanto maior a quantidade de partículas, maior a probabilidade de ocorrência de contato.

Caso não haja energia suficiente para vencer a barreira de atrito estático, não haverá fluxo; do contrário, haverá movimento e, devido à fricção entre os agregados, parte da energia do sistema será dissipada na forma de calor (ANTUNES, 2006).

Por isso, a introdução intencional de bolhas de ar nas argamassas permite aumentar a distância de separação entre os agregados, o que serve como um tipo de lubrificante dos grãos e facilita a mistura e o fluxo.

No estado endurecido, a incorporação de ar, apesar de melhorar algumas propriedades elásticas, térmicas e acústicas, é responsável pela redução da resistência mecânica e pelo aumento da permeabilidade (ROMANO; TORRES; PILEGGI, 2015).

Como as alterações provocadas no estado fresco se refletem nas propriedades após o endurecimento, no cenário atual a preparação dos revestimentos tem se mostrado uma etapa crítica no processo construtivo, pois as argamassas industrializadas apresentam-se muito sensíveis ao processo de mistura, variando o teor de ar incorporado de forma descontrolada (ROMANO et al., 2007b, 2009).

Uma provável causa para tanta variabilidade durante o procedimento de mistura é que pouco se conhece sobre a cinética de incorporação de ar nos materiais cimentícios, e os trabalhos sobre esse tema geralmente são focados na avaliação do desempenho dos materiais no estado endurecido, ilustrando os efeitos da sensibilidade das argamassas na etapa de mistura, e não as causas.

Figura 1 - Alteração das características das argamassas no estado fresco. Em (a) ilustra-se a argamassa misturada sem AIA e em (b) com AIA

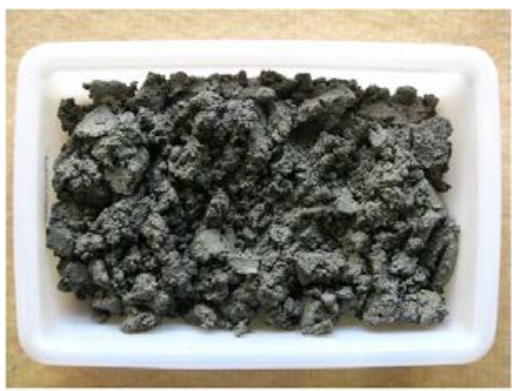

(a)

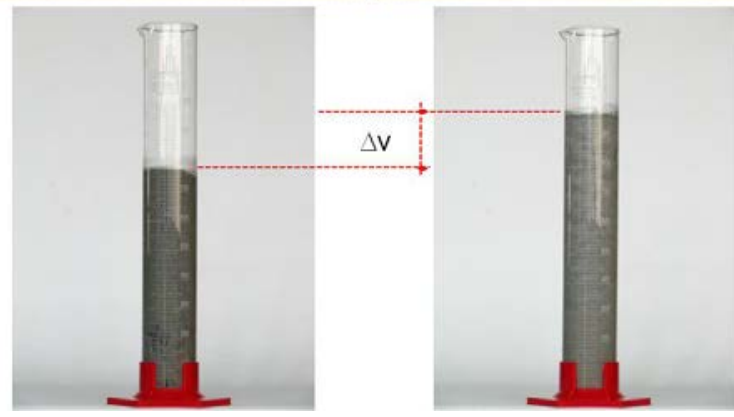

(b) 
Considerando-se que o ar não é incorporado nos agregados, para se compreender a cinética de incorporação é preciso estudar como os aditivos atuam na pasta cimentícia. Seguindo o mesmo raciocínio, no estudo da pasta é preciso primeiro investigar como o ar é incorporado na fase aquosa. Somente após entender a incorporação de ar na fase aquosa e na pasta é possível incorporar agregados para avaliar sistemas complexos e heterogêneos como argamassas, sendo esta a proposta para o desenvolvimento das argamassas apresentada neste trabalho.

\section{Variáveis que interferem na incorporação de ar}

A atuação dos aditivos depende de muitas variáveis, sejam elas intrínsecas das composições ou extrínsecas, como temperatura, tipo de equipamento, energia de mistura, etc.

Optou-se por apresentar inicialmente alguns resultados obtidos em argamassas, principalmente em função da condição de processamento, para salientar os efeitos da incorporação de ar que podem ser observados em obra ou mesmo em laboratório, e mais adiante são apresentados resultados obtidos na pasta e na fase aquosa visando apresentar as causas.

\section{Tipo de misturador e tempo de mistura}

As argamassas geralmente são misturadas nas obras de forma manual ou mecânica. Quando misturadas manualmente, dificilmente é atingido o mesmo nível de desaglomeração e incorporação de ar obtido após a mistura mecânica em função da menor eficiência. Assim, a produtividade do revestimento aplicado é mais baixa. Dessa forma a mecanização da etapa de mistura no processo construtivo representa um avanço no processamento do revestimento.

Os dois tipos de equipamentos mais utilizados em obras para esse fim são as betoneiras (B) e os misturadores de eixo horizontal (EH), e as diferenças conceituais entre eles impõem às argamassas distintas energia e tipo de mistura, interferindo diretamente na eficiência do processamento, conforme pode ser observado na Figura 2 (ROMANO et al., 2009). Nesse caso, três argamassas industrializadas foram misturadas com o teor de água estipulado pelos fabricantes.

Enquanto nos equipamentos de eixo horizontal uma lâmina de mistura empurra as camadas mais externas de argamassa para o interior da massa (PERRY, 1997), no caso das betoneiras a mistura ocorre após sucessivas quedas de parte da argamassa sobre o restante do material, encontrado na parte inferior do equipamento. Por isso, neste segundo caso a inclinação interfere diretamente na eficiência da mistura e incorporação de ar: quanto mais horizontal for a posição da betoneira, menor é a eficiência, pois menor quantidade de argamassa cai sobre o restante. Se a betoneira permanecer voltada para cima $\left(90^{\circ}\right)$, a eficiência é mais baixa ainda, pois não há queda. No entanto, para se atingir maior eficiência é aconselhado que a inclinação seja de no mínimo $15^{\circ}$ (FERRARIS, 2001).

Figura 2 - Efeito do tipo de misturador (e tempo de mistura) na incorporação de ar de argamassas de revestimento industrializadas. Em (a) estão os resultados da mistura realizada em equipamento de eixo horizontal e em (b) nas misturas em betoneira
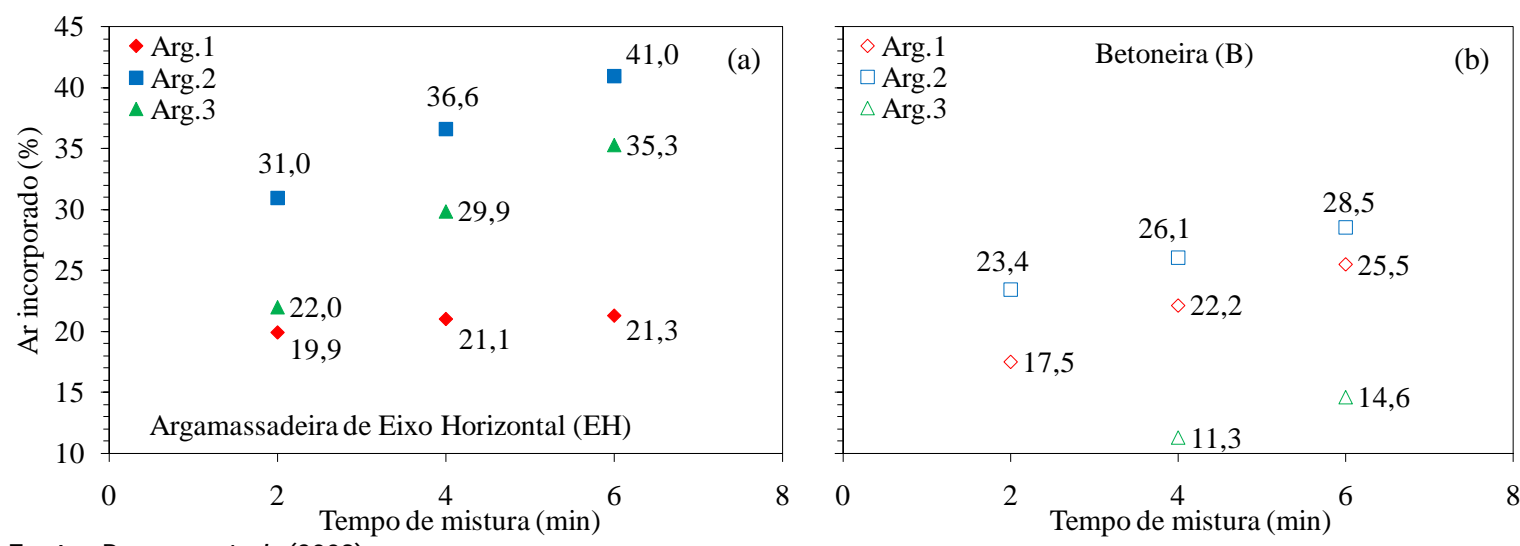

Fonte: Romano et al. (2009). 
A argamassa representada por Arg.1, misturada na argamassadeira EH, apresentou a menor sensibilidade ao processamento, mas, quando misturada na betoneira, a alteração no teor de ar foi a maior de todas, mostrando que, se for processada em betoneira, deve-se ter maior cuidado com a etapa de mistura. Essa informação é interessante e ilustra a importância da especificação do tempo de mistura para cada tipo de equipamento nos sacos de cada produto.

A Arg.2 apresentou níveis de ar muito maiores que as demais, mas não teve a maior variação absoluta do ar incorporado, enquanto a Arg.3, apesar de não ter apresentado os maiores teores de ar entre as argamassas avaliadas, teve a maior sensibilidade ao processamento, principalmente quando misturada no equipamento EH. Para essa composição não foi possível quantificar o teor de ar após 2 min de mistura na betoneira, já que a energia imposta pelo equipamento não foi suficiente para o rompimento dos aglomerados e adequação da argamassa para aplicação. Mesmo assim, a variação absoluta, neste caso entre 4 min e 6 min, já foi elevada.

Nos exemplos apresentados, apesar de o tempo de mistura ter sido a variável de maior impacto nos resultados, o tipo de equipamento empregado também exerceu influência na incorporação de ar, mas não houve tendência clara de maior eficiência na incorporação. Portanto, pode-se inferir que o controle na incorporação de ar depende da adequação da argamassa ao misturador, sendo que o comportamento ideal deve ser o mais próximo possível do obtido para a Arg.1 misturada na argamassadeira EH.

\section{Energia de mistura e tipo de aditivo}

Como visto, o tipo de misturador e o tempo de mistura interferem na incorporação de ar em função das diferenças conceituais entre os equipamentos. No exemplo apresentado anteriormente, para cada equipamento a energia imposta sobre o produto cimentícios foi a mesma. No entanto, um exemplo mais claro sobre a influência da energia de mistura é apresentado na Figura 3. Nesse caso, três argamassas foram misturadas pelo mesmo tempo em um mesmo equipamento, tendo-se variado somente a velocidade de rotação.

O volume de ar incorporado na composição isenta de aditivo não sofre influência da energia de mistura, mas em presença de incorporador de ar há clara tendência de aumento do nível de ar incorporado em função da energia. Adicionalmente, pode-se inferir que a alteração do tipo de aditivo também afeta o volume de ar incorporado devido à eficiência de cada um.

Assim, mesmo com o preciso controle na dosagem das matérias-primas, a energia de mistura é uma variável crítica para o processamento das argamassas e é controlada com pouca frequência nos canteiros de obras (ROMANO et al., 2009; ROMANO, 2013). Para piorar esse cenário, a maioria das argamassas comercializadas no mercado brasileiro apresenta considerável sensibilidade à mistura, principalmente em função da excessiva dosagem de aditivo ou variações das matérias-primas.

\section{Teor de água ou incorporador de ar}

Os exemplos apresentados até aqui indicam o impacto de alterações extrínsecas ao produto, ilustrando o efeito do tipo de equipamento e da energia de mistura. No entanto, no ambiente de obra nem sempre as argamassas são misturadas com o mesmo teor de água.

Na Figura 4 é apresentado um exemplo do impacto da quantidade de água de amassamento na incorporação de ar de argamassas com distintos teores de aditivo. A avaliação foi realizada em função do tempo de mistura.

Para o menor teor de água, a quantidade de incorporador de ar foi irrelevante na geração das bolhas, mas com o aumento da quantidade de água percebeu-se claramente o efeito da variação do teor de aditivo, o que indica que a geração das bolhas depende da presença de água livre na suspensão.

Ademais, independentemente do teor de aditivo ou da quantidade de água, as argamassas mostraram-se sensíveis ao tempo de mistura, fato já apresentado anteriormente e comumente reportado no setor de construção civil em função da utilização de dosagem excessiva de aditivo.

\section{Distribuição granulométrica}

A distribuição granulométrica resultante na formulação interfere na quantidade de água necessária para o amassamento, e quanto maior a quantidade de finos, maior a necessidade de água para adquirir a consistência adequada.

Outra informação que merece destaque é que, quanto maior o volume de pasta entre os agregados, maior a possibilidade de incorporação de ar e maior a sensibilidade às variáveis de processamento. 
Figura 3 - Efeito da energia de mistura (indicada pela velocidade de rotação) na incorporação de ar em argamassas de revestimento

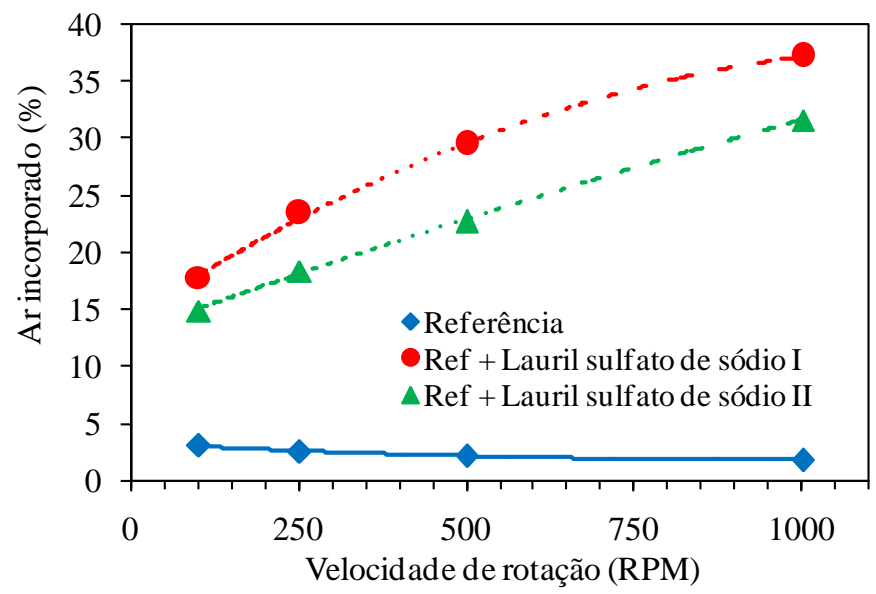

Figura 4 - llustração do efeito da variação da massa de água (15\% ou 16\%), do teor de incorporador de ar ( $0,3 \%$ ou $0,45 \%)$ e do tempo de mistura na incorporação de ar em argamassas

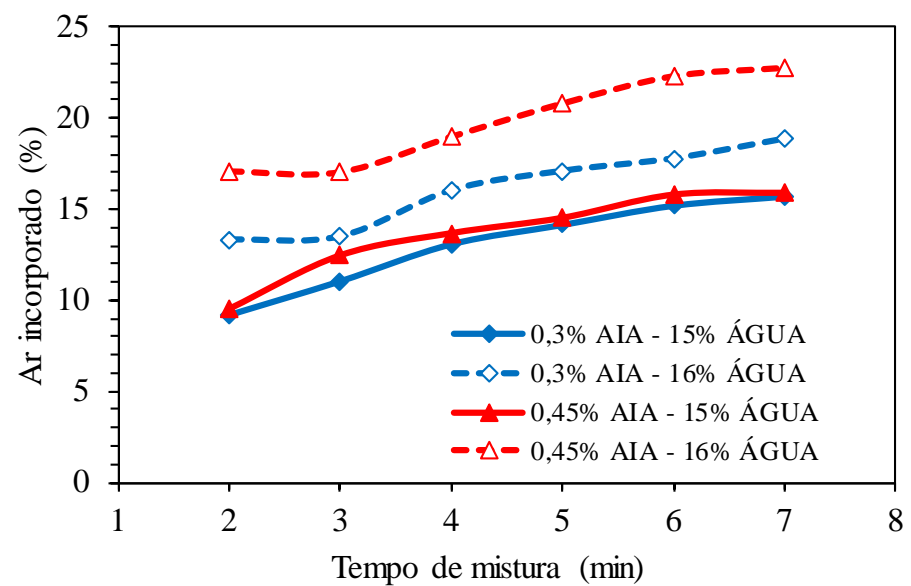

No entanto, mantendo a quantidade de água e o teor de pasta constantes, e alterando a distribuição granulométrica dos agregados, percebe-se que a descontinuidade granulométrica resulta em menor viscosidade e tensão de escoamento da argamassa e maior facilidade para a mistura, conforme ilustrado na Figura 5, a partir de resultados de reometria rotacional: quanto maior o torque, maior a estimativa de energia necessária para a mistura.

Quando não se utiliza incorporador de ar, o impacto das alterações granulométricas dos agregados é intensificado em função da proximidade das partículas e da maior força de atrito entre os grãos.

À medida que se utiliza o aditivo, o impacto provocado em função das diferenças granulométricas é suavizado, sendo menor quanto maior o teor de AIA. No entanto, o excesso de aditivo, apesar de tornar as argamassas mais robustas, afeta a sensibilidade da mistura, tornando as composições muito vulneráveis às condições de processamento.
Os resultados apresentados acima foram adaptados de Romano, Torres e Pileggi (2015), em que foram avaliadas também as propriedades no estado endurecido, constatando-se que as alterações granulométricas apresentaram maior impacto na permeabilidade ao ar (parâmetro relacionado com a durabilidade) do que na resistência mecânica, no módulo de elasticidade ou na resistência de aderência à tração.

Sendo assim, é muito importante que durante a produção das argamassas o controle granulométrico seja adequado, assim como a dosagem do incorporador de ar. Se o aditivo estiver sendo utilizado para minimizar desajustes granulométricos, além das funções já conhecidas, essa estratégia pode ser ainda mais prejudicial para o desenvolvimento das composições, resultando em produtos com maior sensibilidade ao processamento nas obras. 
Figura 5 - Efeito da distribuição granulométrica dos agregados no perfil de mistura de argamassas isentas de aditivo (a), aditivadas com o teor ideal de incorporador de ar (b) e aditivadas com excesso de incorporador de ar (c)
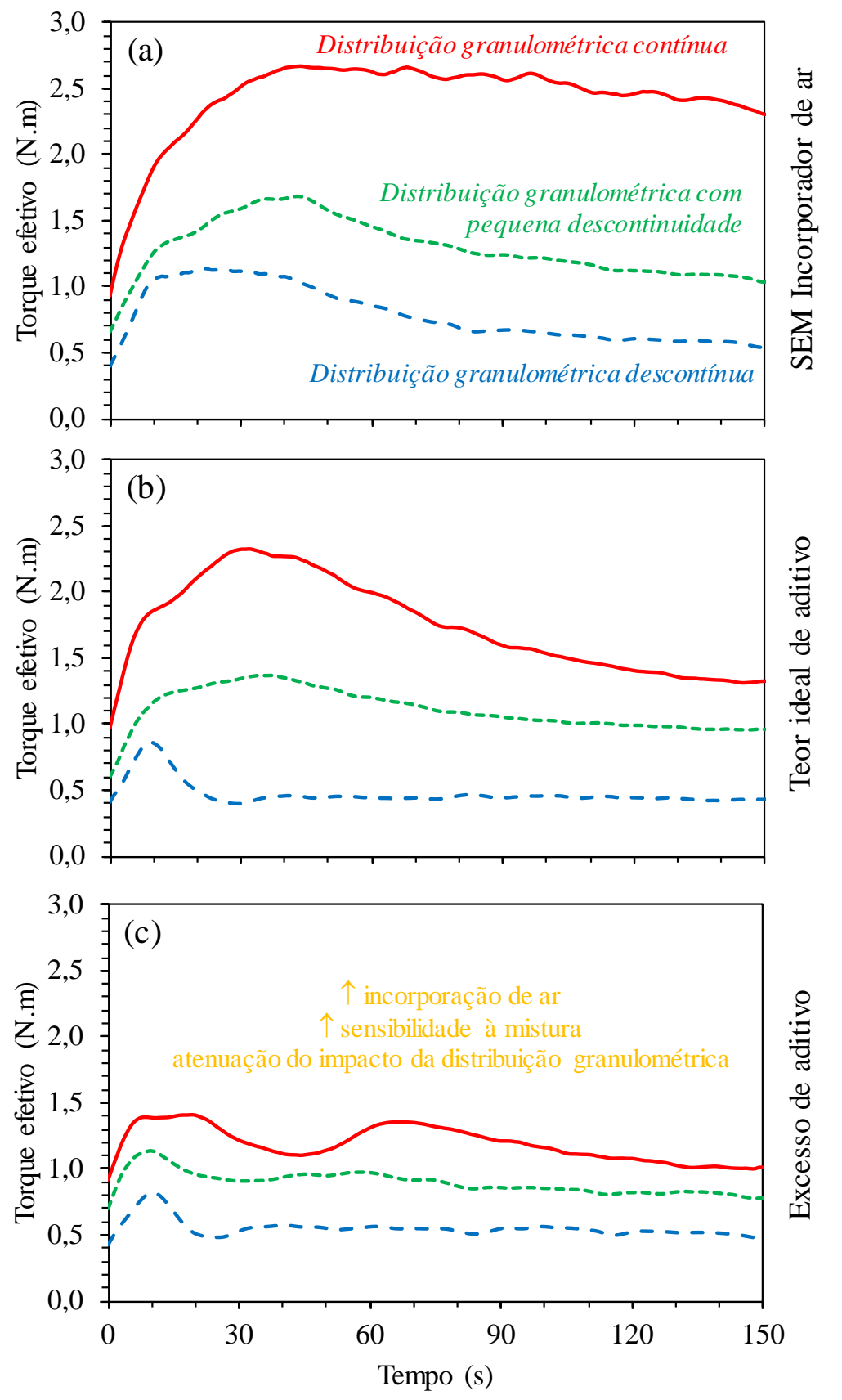

Com as informações apresentadas até este ponto fica muito claro que a incorporação de ar nas argamassas é extremamente dependente tanto de fatores intrínsecos das formulações, como tipo e teor de aditivo, distribuição granulométrica, etc., quanto de fatores extrínsecos, como tipo de equipamento, tempo e energia de mistura, teor de água, etc.
No entanto, independentemente da variável do processo de fabricação do produto ou processamento do revestimento nas obras, o fato é que as bolhas de ar são incorporadas na fase de pasta das argamassas, e a melhor forma de se compreender o que está ocorrendo na argamassa como um todo em função da incorporação de ar é avaliar as propriedades das pastas cimentícias isoladamente. 


\section{Incorporação de ar na pasta cimentícia}

De acordo com Ramachandran (1984), as bolhas de ar são ancoradas na superfície das partículas do cimento criando pontes entre elas, mas, apesar de essa afirmação ser muito utilizada para descrever a interação partícula-bolha, trata-se de uma descrição simplista do que ocorre nas pastas. Conforme descrito abaixo e ilustrado mais adiante, na Figura 6, os aditivos em suspensão podem:

(a) formar micelas que são ancoradas na superfície do cimento;

(b) formar micelas livres na pasta (sem ancoramento), que coalescem e colapsam facilmente;

(c) estar livres, sem a formação das micelas;

(d) estar ancorados na interface cimento-ar;

(e) formar aglomerados micelares sem ancoramento no cimento; e

(f) formar aglomerados micelares ancorados nas partículas.

A maior parte dos incorporadores de ar permanece ancorada na superfície do cimento na forma de micelas, mas mesmo em pequenas quantidades livres na solução é suficiente para alterar a tensão superficial da água de amassamento.

As micelas não ancoradas coalescem facilmente, apresentam maior mobilidade entre as partículas e, por isso, colapsam rapidamente. Podem se comportar como agregados compressíveis e perturbar de forma indesejada o fluxo das partículas, assim como os íons dissociados do aditivo podem afetar as propriedades superficiais do meio líquido. No caso das bolhas pequenas, a busca por um estado de menor energia interna é mais intensa que para as bolhas com maior raio, o que favorece a tendência natural de coalescência.

Se a molécula do incorporador de ar apresentar caráter iônico, as bolhas irão adquirir carga na superfície, fazendo com que duas bolhas se mantenham afastadas eletrostaticamente durante a mistura, evitando a coalescência e aumentando a estabilidade (RAMACHANDRAN, 1984).

Alguns autores citam que a presença de incorporador de ar nas pastas é responsável pela melhor estruturação do sistema cimentício, tornando-as mais viscosas (RIXON; MAILVAGANAN, 1999; WHITING; NAGI, 1998; ANTUNES, 2006). No entanto, essa informação não pode ser tomada como regra para todos os casos, pois as alterações nas propriedades de pastas com AIA dependem de muitas variáveis, como tipo de cimento, tipo e teor de aditivo, teor de água, temperatura, etc. (ROMANO et al., 2011a).

Confusões como essa são frequentes em pesquisas sobre incorporação de ar em materiais cimentícios, e por isso os problemas continuam ocorrendo sem soluções definitivas para o assunto, ou, pelo menos, respostas coerentes sobre os problemas.

Cada tipo de cimento, ou matéria-prima inorgânica, apresenta diferente composição em relação a distribuição granulométrica, área específica, densidade, teor de álcalis, etc., e isso afeta diretamente na incorporação de ar.

Pode-se dizer que para o mesmo tipo de insumo existem consideráveis variações físicas e químicas, dependentes do processo de produção.

Quanto mais fino o material e maior sua área específica, maior a necessidade de água para o amassamento e maior a necessidade de AIA para a obtenção do mesmo teor de ar (RIXON; MAILVAGANAN, 1999).

\section{Figura 6 - Ilustração do efeito da presença de incorporador de ar na pasta cimentícia}

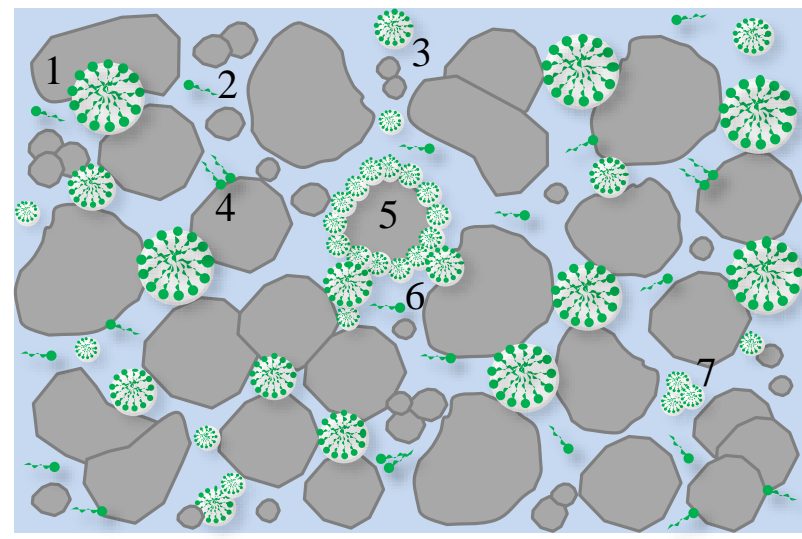

1. Ancoramento das micelas nas partículas em suspensão do cimento

2. AIA livres (não formarammicelas)

3. Micelas livres na pasta (não ancoradas)

4. AIA ancorados na partícula de cimento

5. Micelas o redor do grão de cimento

6. Agregados micelares (ancorados)

7. Agregados micelares (livres)

cimento

micela / bolha de ar

água 
Na Figura 7 são apresentados exemplos do efeito do tipo de cimento e variação da temperatura na incorporação de ar em materiais cimentícios (ROMANO; PILEGGI, 2012).

Nas amostras misturadas sem o aditivo não foram observadas consideráveis alterações no teor de ar, mas em presença de incorporador de ar os volumes de ar incorporado foram distintos e dependentes do tipo de cimento e da temperatura. Nesses casos não foram observadas diferenças consideráveis em função do tipo de aditivo, mas sabe-se que essa é uma variável que impacta na incorporação de ar, conforme já reportado anteriormente.

Da mesma forma, a temperatura da água ou do ambiente afeta diretamente a formação e a estabilidade das bolhas, pois altera a viscosidade da solução. Com isso, o movimento de drenagem de líquidos na direção das bordas de Plateau, que é responsável pela diminuição da espessura e da resistência mecânica da película que envolve as bolhas de ar, é afetado, o que facilita a coalescência (FORTES; CORGHLAN, 1994).

Bolhas de ar geradas em líquidos com baixa viscosidade apresentam menor estabilidade que bolhas geradas em líquidos com maior viscosidade. Assim, para a obtenção de materiais cimentícios que podem ser processados e aplicados tanto em climas quentes quanto em climas frios, deve-se utilizar aditivos que sejam mais estáveis em relação à variação de temperatura.

Conforme ilustrado anteriormente, na Figura 7, apesar de haver diferentes interações dos aditivos com o tipo de cimento, os incorporadores de ar não foram sensíveis à temperatura. Porém, como pode ser observado na Figura 8, essa informação não é regra geral (ROMANO, 2013), visto que o aumento da temperatura resultou em redução do teor de ar somente em um dos sistemas avaliados, o que mostra a sensibilidade do aditivo à condição climática.

Figura 7 - Efeito do teor de cimento e da temperatura na incorporação de ar nos materiais cimentícios
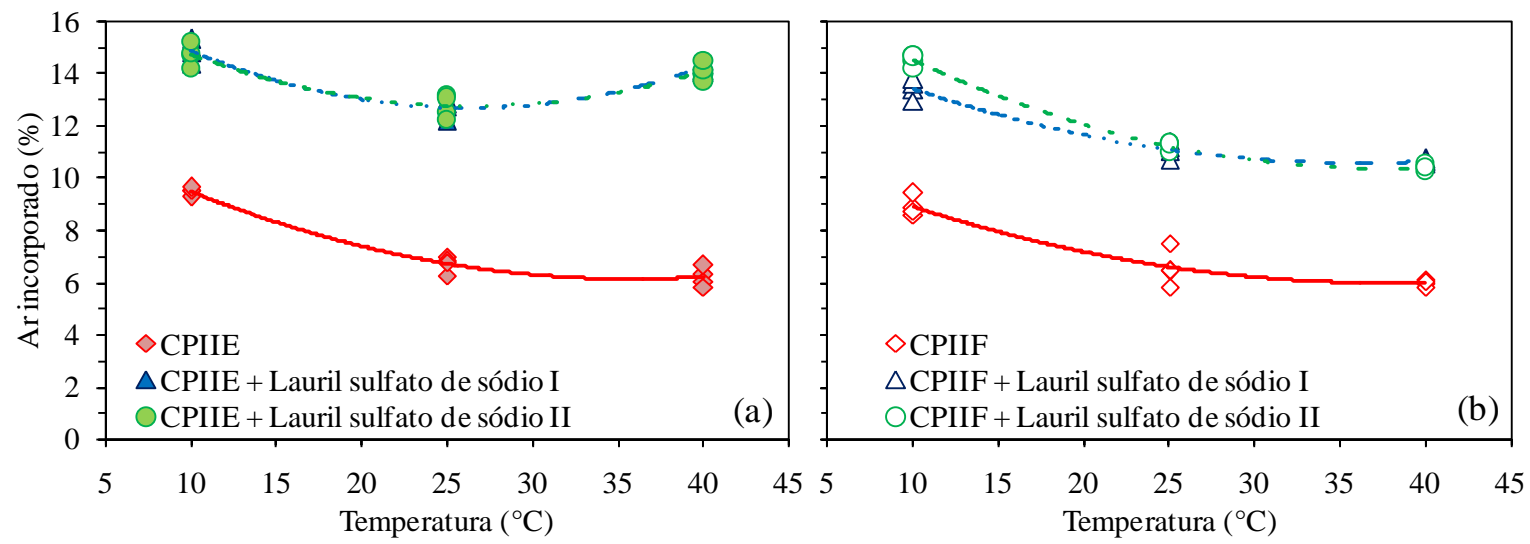

Figura 8 - Efeito da temperatura na incorporação de ar em sistemas cimentícios. Em (a) é apresentado o resultado para um aditivo à base de lauril sulfato de sódio com $100 \%$ de moléculas orgânicas e em (b) com outro aditivo de mesma base molecular, porém com somente $67 \%$ de material orgânico
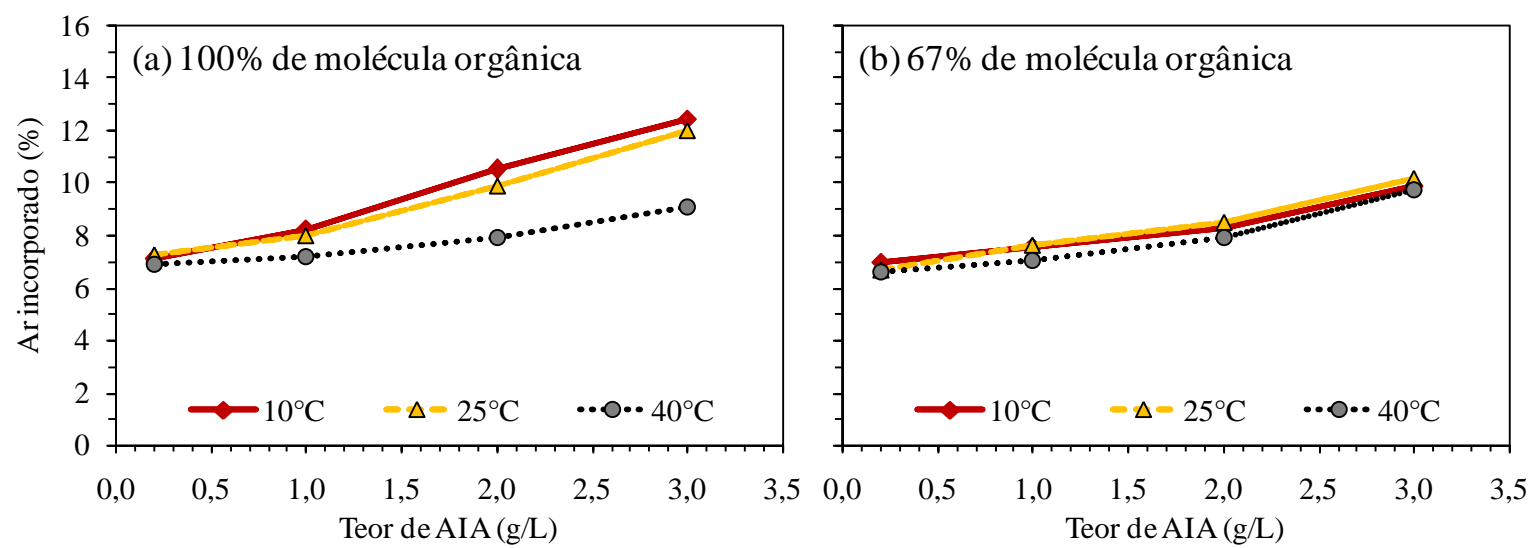
Independentemente disso, a camada de água ao redor da bolha pode estar cheia de produtos de hidratação do cimento, servindo para separá-las e deflocular o sistema (RAMACHANDRAN, 1984; RIXON; MAILVAGANAN, 1999; WHITING; NAGI, 1998).

Podem ainda ser precipitados compostos de hidratação do cimento na superfície ou no interior das bolhas, resultando, após o endurecimento, em poros com características distintas, dependentes do tipo de aditivo, do tipo de cimento e das interações entre eles, conforme apresentado na Figura 9.

A formação dos cristais foi muito mais intensa nas amostras com o cimento composto de pozolana em comparação com os cimentos compostos por filler ou escória, podendo até, com o passar do tempo, auxiliar na colmatação dos poros gerados pela incorporação intencional de ar. Deve ser salientado que os resultados obtidos se referem aos ligantes avaliados, não sendo regra geral outros cimentos compostos com os mesmos tipos de adição; pretendeu-se ilustrar que as diferentes interações dos aditivos com os ligantes resultam em microestruturas porosas distintas.

Nesses casos, todas as misturas foram feitas em temperatura ambiente, e as amostras curadas em $25^{\circ} \mathrm{C}$ e $98 \%$ de umidade relativa, mas no caso de alterações na condição de cura o desenvolvimento da microestrutura porosa é também afetado, conforme ilustrado na Figura 10, a partir da análise dos resultados de porosimetria de intrusão de mercúrio.

Tal avaliação é importante porque a distribuição e o tamanho dos poros na estrutura afetam diretamente a absorção por capilaridade e o transporte de umidade, fenômenos relacionados com resistência mecânica, módulo de elasticidade, permeabilidade e, consequentemente, durabilidade, degradação e tempo de vida das edificações (ARANDIGOYEN; ALVAREZ, 2007).

Figura 9 - Ilustração dos poros gerados na microestrutura de pastas formuladas com diferentes tipos de cimento e incorporadores de ar à base de lauril sulfato de sódio

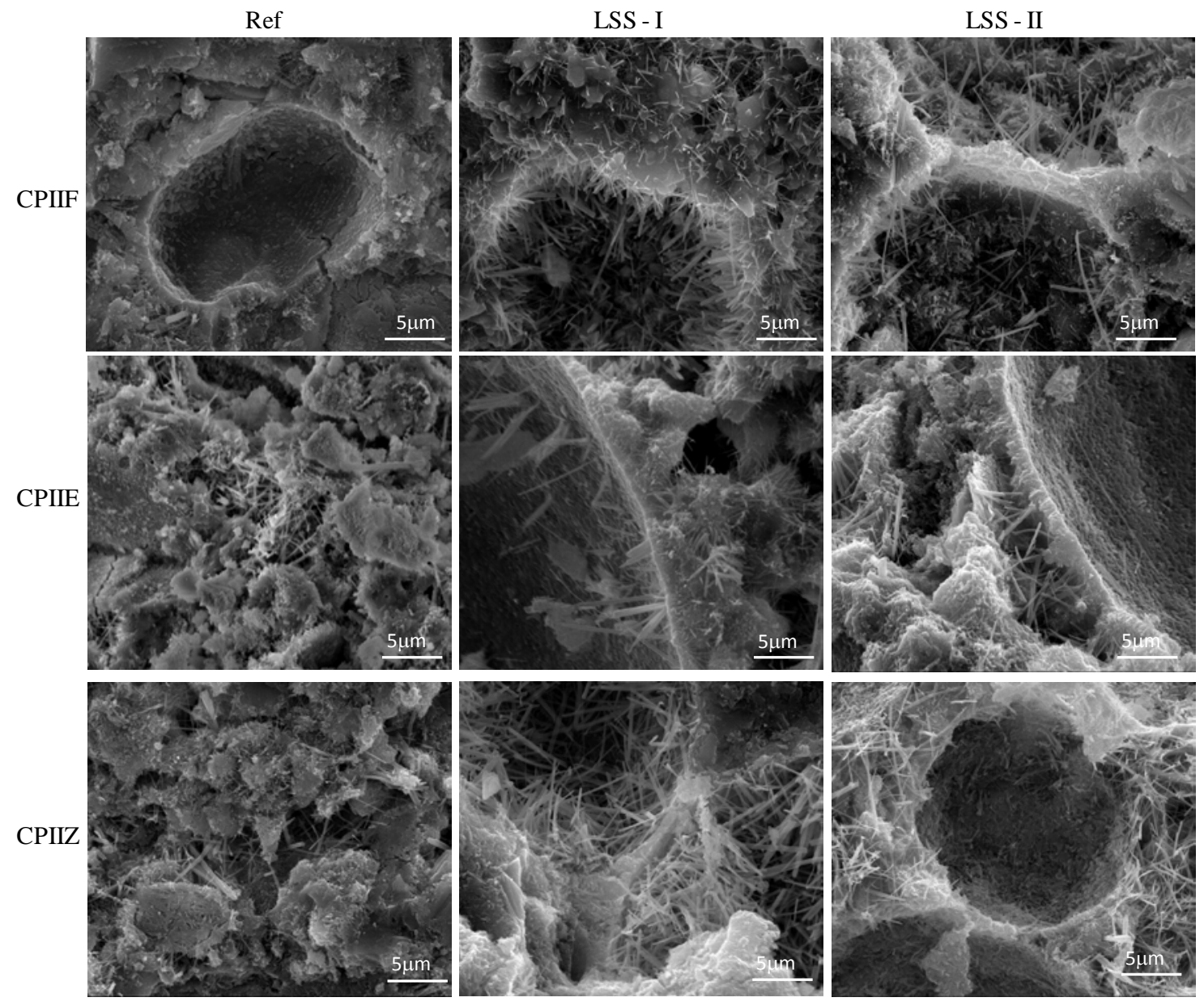


Figura 10 - Efeito da temperatura de cura na distribuição de tamanho de poros na microestrutura das pastas cimentícias

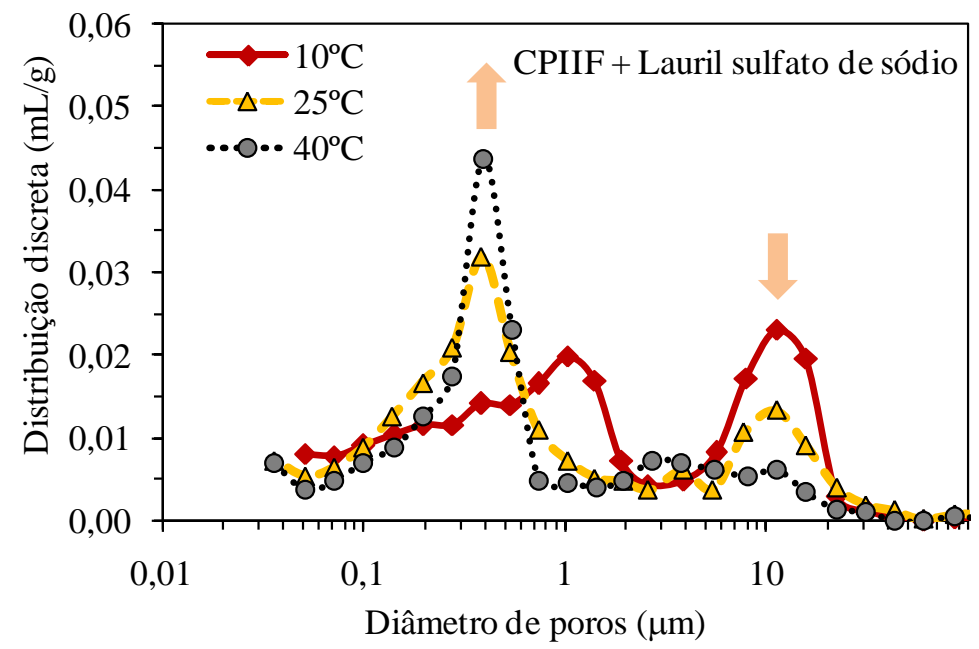

De acordo com Kumar e Bhattacharjee (2003), a distribuição de poros dos compostos à base de cimento é dividida em quatro tipos, dependentes do diâmetro:

(a) poros de gel (microporos com diâmetros entre $0,5 \mathrm{~nm}$ e $10 \mathrm{~nm}$ );

(b) poros capilares (mesoporos com diâmetros entre $10 \mathrm{~nm}$ e $10 \mu \mathrm{m})$;

(c) macroporos gerados pela incorporação de ar; e

(d) macroporos gerados devido a compactação inadequada.

Nos sistemas apresentados acima duas classes de poros foram observadas, independentemente da temperatura de cura:

(a) até $1 \mu \mathrm{m}$, representando os poros capilares; e

(b) entre $5 \mu \mathrm{m}$ e $30 \mu \mathrm{m}$, ilustrando o efeito da presença das bolhas de ar (CEBECI, 1981).

Mesmo não sendo observados poros de gel, não quer dizer que não exista nanoporosidade na estrutura gerada; isso pode se dever somente à restrição da faixa de detecção do equipamento utilizado.

A quantidade de poros gerados pela ação dos aditivos foi maior nas pastas curadas a $10^{\circ} \mathrm{C}$, enquanto a quantidade de poros capilares foi maior nas amostras curadas na temperatura mais alta.

Fica claro então que o aumento da temperatura resulta em uma microestrutura em que os poros mais finos foram predominantes em relação à microestrutura gerada nas pastas curadas a $10^{\circ} \mathrm{C}$

IDIAMOND, S.; DOLCH, W. L. Generalized Log-Normal Distribution of Pore Sizes in Hydrated Cement Paste. J ournal of Colloid and Interface Science, v. 38, n. 1, p. 234-244, 1972.
(VYDRA et al., 2007; ROMANO et al., 2011b) Portanto, conforme já citado por Cebeci (1981), pode-se afirmar que o ar incorporado introduz somente os poros maiores na estrutura, aqueles que podem ser observados a olho nu.

Pode ser que esses poros não tenham sido detectados nas pastas curadas a $40^{\circ} \mathrm{C}$ por estarem isolados no interior da microestrutura, sem conectividade com a superfície, onde o mercúrio não pode ser intrudido. Independentemente disso, os resultados divergem do que fora observado por Vydra et al. (2007) ou Diamond e DOlch $\left(1972^{1}\right.$ apud SELLEVOLD, 1974), quando avaliaram pastas cimentícias com ar incorporado curadas em distintas temperaturas.

O fato é que o desenvolvimento da microestrutura porosa não é trivial e depende de muitos fatores, como tipo e teor de cimento, tipo e teor de incorporador de ar, teor de água, energia de mistura, etc., variáveis comumente encontradas no setor construtivo. Essa microestrutura, por sua vez, pode governar as características das argamassas no estado endurecido e, consequentemente, impactar no desempenho dos materiais cimentícios em uso.

Da mesma forma que fora descrito para as argamassas (salientando que as bolhas são geradas na fase pasta), para melhor compreensão da incorporação de ar nas pastas deve-se avaliar a ação dos aditivos na água sem a presença do cimento.

\section{Incorporação de ar na água}

As argamassas apresentam certo volume de ar incorporado mesmo sem a utilização do 
incorporador de ar, resultado do cisalhamento da composição após a adição da água, e não sofrem influência nem do tempo de mistura nem da energia imposta à massa. Esse fenômeno é explicado porque há incorporação de ar na água mesmo sem a presença de tensoativos, ou seja, com a agitação o ar que está na superfície é trazido para dentro do líquido e, devido à formação de uma película entre a água e o ar, há formação de bolhas no interior do líquido.

Enquanto há agitação, as bolhas permanecem em solução, mas quando é cessada, a película que aprisiona o ar dentro das bolhas é rompida rapidamente, resultando na colapsação, conforme esquema ilustrativo apresentado na Figura 11.

A taxa de colapsação de bolhas ou de cremeação (flutuação das bolhas dispersas para a superfície do líquido) é dependente da viscosidade do meio líquido, sendo mais lenta quanto maior a viscosidade. É dependente também da quantidade de sólidos em suspensão (que podem dificultar o deslocamento das bolhas à superfície), da temperatura, da presença de íons e da utilização de incorporadores de ar. De qualquer forma, quando as bolhas de ar são geradas sem a utilização de aditivo para tal função, são instáveis e de colapsação rápida.

Quando os incorporadores de ar são adicionados à água, os fenômenos de hidrofilicidade e hidrofobicidade acontecem, alterando a tensão superficial do líquido, que, por sua vez, é responsável pela maior capacidade de molhamento e espumante gerada na solução.

Conforme ilustrado na Figura 12, há adsorção dos aditivos na superfície água-ar, o que reduz a tensão superficial, e com a agitação mecânica há formação de bolhas de ar mais estáveis.

As etapas da vida da espuma são exatamente as mesmas apresentadas para as bolhas instáveis formadas na solução sem aditivo (e serão discutidas com mais detalhes mais adiante). Porém, como neste caso há uma espécie química que mantém a película superficial estável por mais tempo, a taxa de colapsação das bolhas é mais lenta.

Tal estabilidade depende do tipo e concentração do aditivo, pois essas variáveis têm efeito na tensão superficial do meio líquido. Inicialmente, os aditivos são adsorvidos na superfície água-ar, e a tensão superficial decresce rapidamente. A partir de determinada concentração, dependente do tipo de aditivo, cria-se uma camada monomolecular do incorporador de ar, e a tensão superficial da água decresce linearmente com o logaritmo da concentração; segundo a isoterma de Gibbs, isso indica que a concentração superficial permanece constante.

\section{Figura 11 - Geração de ar em água isenta de aditivo durante a agitação mecânica e posterior colapsação}

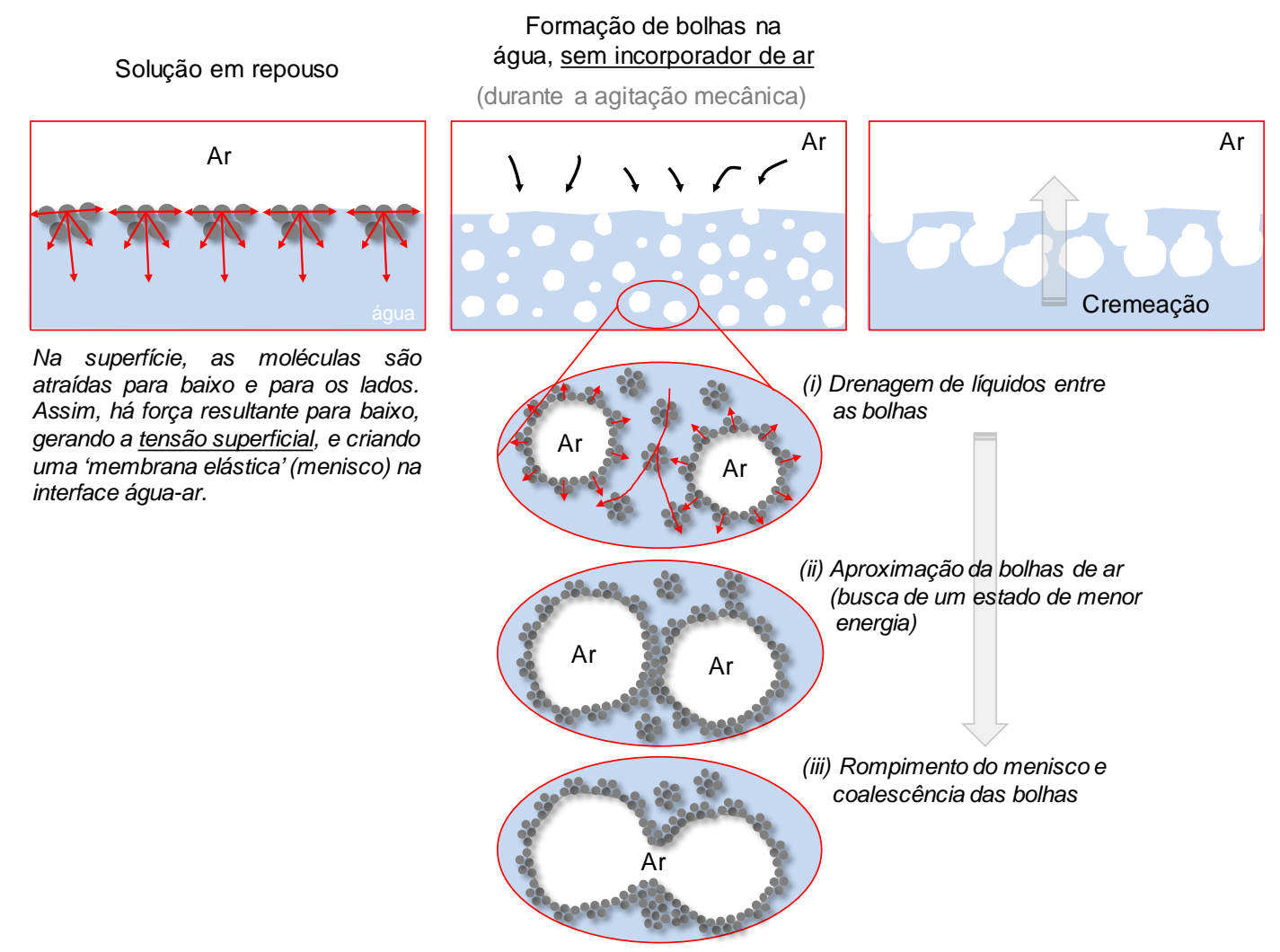


Figura 12 - Geração de ar em água com incorporador de ar. llustração da adsorção do aditivo na superfície água-ar
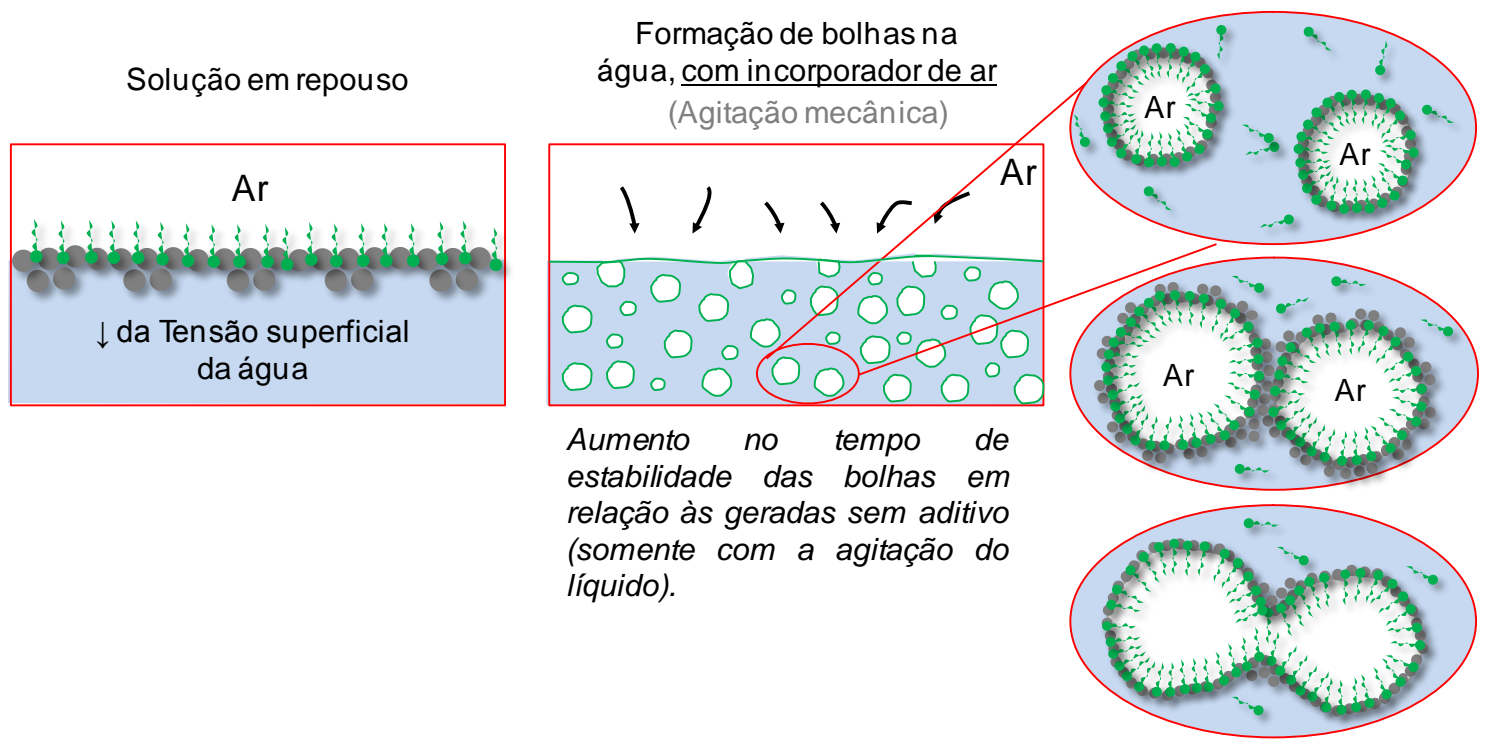

A partir da concentração micelar crítica (CMC) há saturação de moléculas de incorporador de ar na fase aquosa, e a tensão superficial permanece constante mesmo com o aumento da concentração de aditivo (SALAGER, 1993).

Pode-se inferir que o teor ideal de incorporador de ar a ser utilizado nas composições cimentícias deverá ser no máximo igual a sua concentração micelar crítica. $\mathrm{O}$ excesso de moléculas livres no sistema cimentício pode resultar em alterações indesejadas nas propriedades nos estados fresco e endurecido, como instabilidade do ar, falta de controle do ar durante a mistura, aumento excessivo da porosidade e da permeabilidade ao ar, e, consequentemente, redução do desempenho e da durabilidade.

A formação e a estabilização das bolhas dependem do tipo de incorporador de ar, da presença de íons provenientes do cimento e das interações entre os aditivos e os íons. Por exemplo, quando alguns incorporadores de ar são misturados com água dura, rica em carbonato de cálcio, a capacidade espumante é reduzida devido à dissolução dos íons $\mathrm{Ca}^{2+}$ na água (PEPER, 1958; ZHANG et al., 2003, 2004). Sendo assim, pode-se dizer que a qualidade da água (presença de eletrólitos no meio aquoso) afeta a capacidade espumante dos aditivos.

A presença de íons tende a diminuir a solubilidade de muitas espécies químicas na água e pode inclusive resultar na formação de sais insolúveis (precipitados). Os eletrólitos reduzem a solvatação da porção hidrofílica do aditivo e incorporam maior concentração de íons na superfície das micelas, o que reduz a repulsão eletrostática entre as partes hidrofílicas carregadas. Ambos os fenômenos favorecem a formação de micelas e, por isso, em presença de eletrólitos a CMC é mais baixa, conforme apresentado na Figura 13 (SALAGER, 1993, 2002).

Uma forma simples para determinar a CMC é mediante a quantificação da condutividade elétrica das soluções (ROMANO, 2013), pois, devido às peculiaridades das moléculas, os incorporadores de ar associam-se espontaneamente em solução aquosa a partir de determinada concentração, a qual depende da estrutura do aditivo (tamanho da cadeia hidrocarbônica) e das condições do meio (concentração iônica, contraíons, temperatura, etc.). Neste ponto há descontinuidade da curva de condutividade, pois:

(a) as micelas são espécies pouco ionizadas; e

(b) as micelas que se formam são grandes (em relação aos monômeros), sendo sua mobilidade iônica menor que a do monômero.

Tal alteração deve-se à redução da espessura da dupla camada elétrica ao redor das micelas, o que resulta na diminuição das forças de repulsão entre os grupos hidrofílicos vizinhos, na redução da solubilidade do grupo hidrofílico e no aumento da interação entre a porção lipofílica e a fase aquosa, podendo produzir micelas com formato não esférico (SALAGER, 1993).

Para se ter uma ideia, na Figura 14 são apresentadas as ilustrações da formação de micelas em água deionizada (a) ou saturada de íons $\mathrm{Ca}^{2+}$ (b). Abaixo estão as fotos das gotas das respectivas soluções, que salientam as diferenças no ângulo de contato e, consequentemente, na tensão superficial. 
Figura 13 - CMC determinada a partir do ensaio de condutividade - os índices da CMC indicam ${ }^{1}$ primária $e^{2}$ secundária - na parte de cima estão os resultados dos testes nas soluções com água deionizada e na de baixo com a solução saturada de íons $\mathrm{Ca}^{2+}$ dissociados do cimento
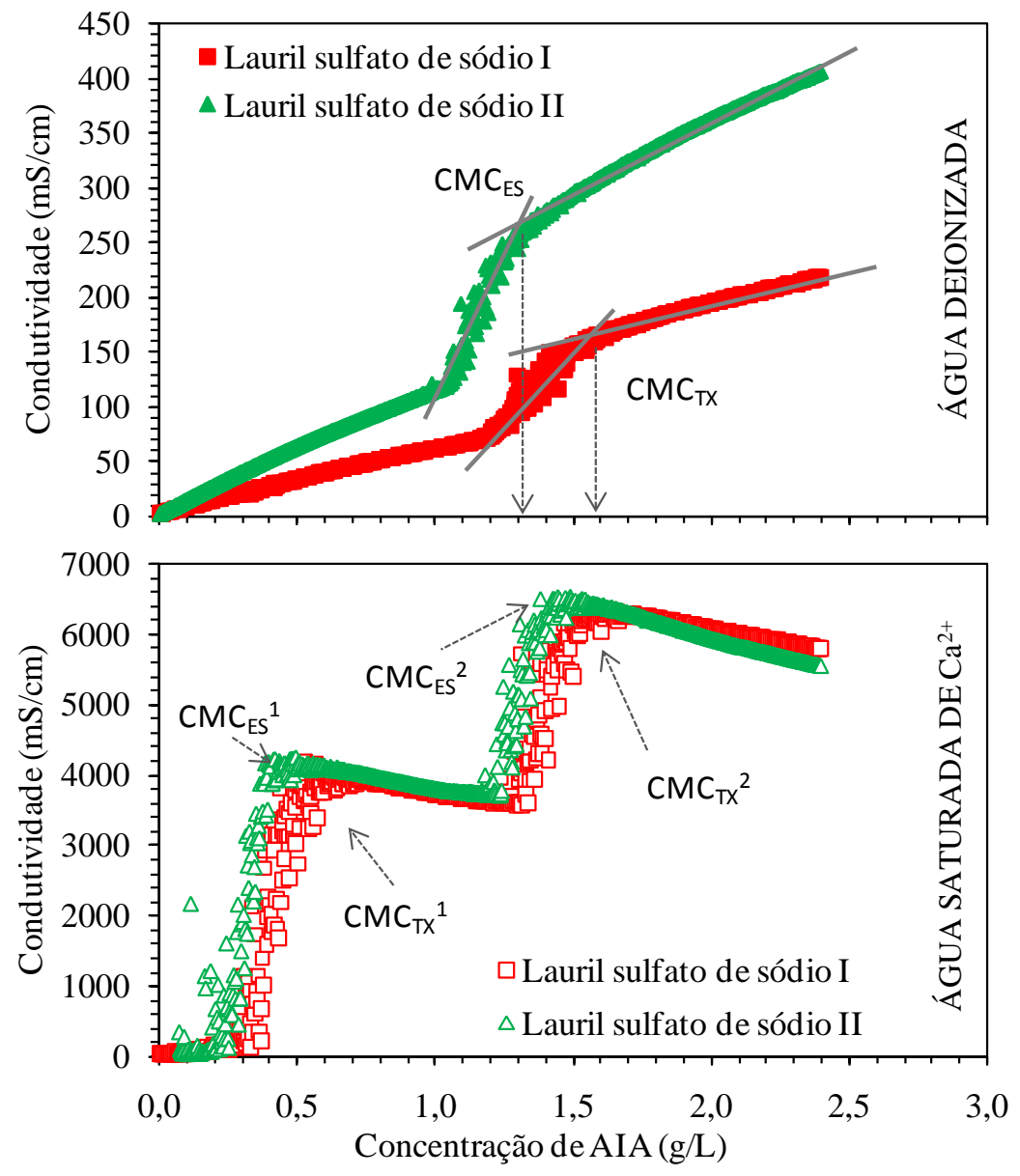

Figura 14 - llustração da formação das micelas na solução de água isenta de íons (a) ou saturada de íons $\mathrm{Ca}^{2+}$ provenientes do cimento (b). Abaixo são apresentadas as fotos das gotas resultantes em cada solução

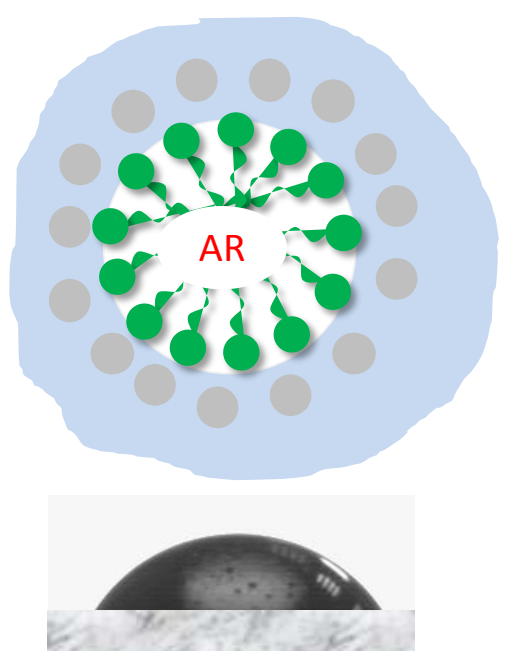

(a)

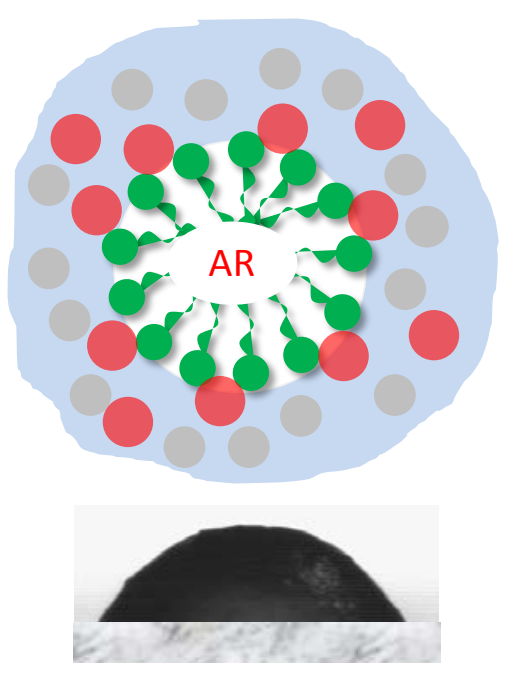

(b)

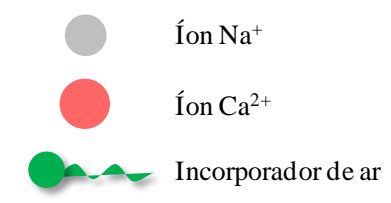


Apesar de haver redução na CMC, o que pode induzir ao erro de se imaginar que a utilização de água dura nas composições cimentícias pode diminuir a quantidade de aditivo necessário para a geração de ar, a estabilidade das bolhas é muito menor que a das bolhas geradas em água isenta dos eletrólitos, pois a película que as envolve é mais fina e menos resistente, induzindo a rápida colapsação: as bolhas são geradas e instantaneamente colapsadas (PEPER, 1958; ZHANG et al., 2003, 2004).

De acordo com a literatura, incrementos dos aditivos acima da CMC pouco afetam a incorporação de ar, mas interferem de forma crescente na condutividade ou na formação de espécies químicas insolúveis. No entanto, conforme ilustrado na Figura 15, deve-se tomar cuidado com esse tipo de afirmação, pois a incorporação de ar segue ocorrendo mesmo com teor de aditivo maior que a CMC para a água deionizada e/ou é pouco efetiva na solução saturada de eletrólitos.

Por outro lado, as afirmações encontradas em literatura estão coerentes no que diz respeito à formação de espécies químicas insolúveis, conforme ilustrado na Figura 16. A interação entre o cátion proveniente da dissociação do cimento e o ânion da dissociação do incorporador de ar resulta na formação de precipitados na solução aquosa; consequentemente, a quantidade efetiva de aditivo para espumação é reduzida.

Por isso, pode-se dizer que a qualidade da água altera a quantidade de incorporador de ar efetivo para geração das bolhas de ar, interferindo na incorporação de ar (ROMANO, 2013).

Figura 15 - Efeito da qualidade da água na incorporação de ar. À esquerda é ilustrado o volume de espuma gerado na água isenta de íons, e à direita, o volume de ar incorporado na solução saturada de íons $\mathrm{Ca}^{2+}$ provenientes do cimento
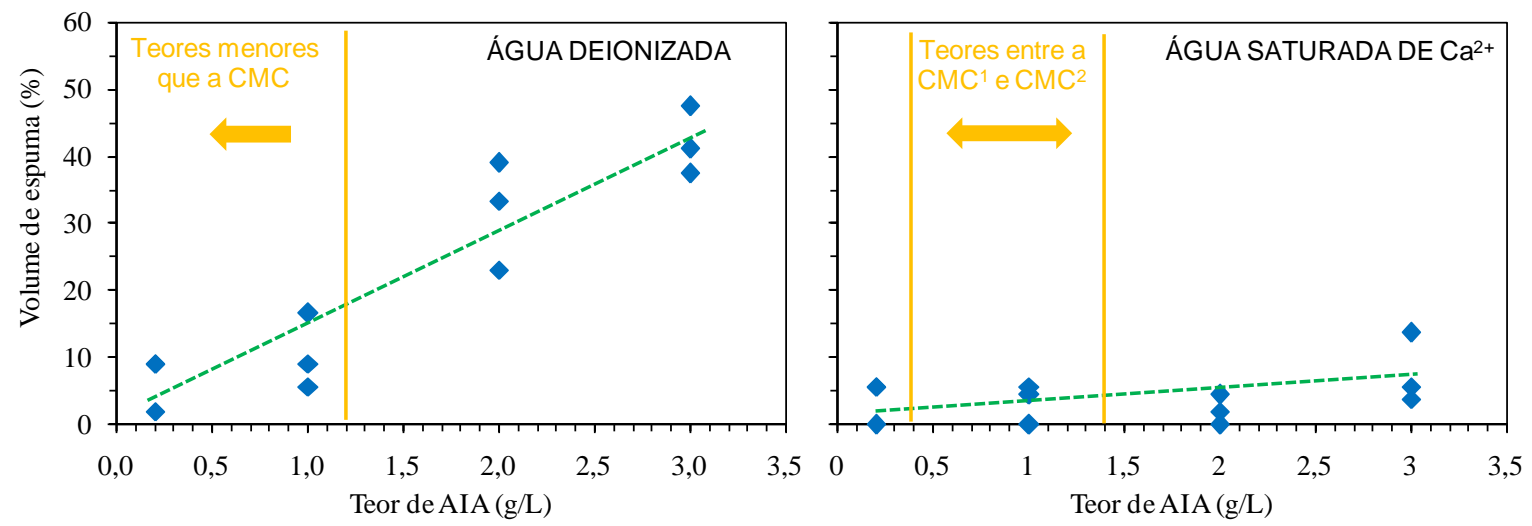

Figura 16 - Consumo de íons Ca2+em função do aumento do teor de ânions lauril sulfato (R-SO4-) na solução de água saturada

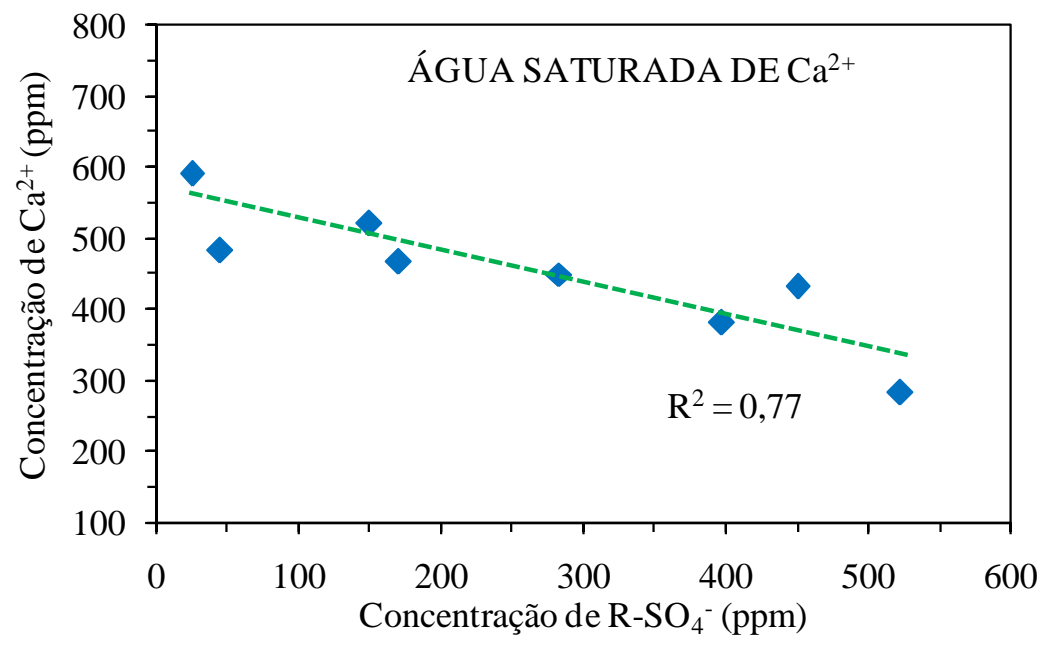


Seja para aditivos iônicos ou não iônicos, a CMC diminui e depois aumenta em função da temperatura. Esse valor mínimo se deve a dois efeitos opostos, pois o aumento da temperatura resulta em:

(a) redução da hidratação dos grupos hidrofílicos; e

(b) aumento da desorganização das moléculas de água que se encontram ao redor da porção polar do aditivo.

Enquanto o primeiro ocasiona diminuição da CMC, o segundo desfavorece a formação das micelas, resultando em aumento. Portanto, o valor mínimo de CMC observado em função do aumento de temperatura equivale a uma competição entre os dois fenômenos: para menores temperaturas prevalece a redução da hidratação dos grupos hidrofílicos, enquanto para maiores temperaturas a desorganização das moléculas de água é predominante.

Conforme ilustrado anteriormente, as argamassas são sensíveis à condição climática e tal sensibilidade pode ser explicada avaliando-se a geração de espuma aquosa na água em distintas temperaturas, conforme apresentado na Figura 17.

Conforme observado, os resultados obtidos na pasta são reflexos das alterações ocorridas na fase aquosa, e o aditivo que apresentou sensibilidade à condição climática na água foi sensível também quando o cimento foi adicionado na composição.

Deve ser salientado que o aumento da temperatura por si só já promove aumento tanto na tensão de escoamento quanto na viscosidade das pastas de cimento, independentemente da presença, ou não, de incorporadores de ar. Por isso, quando um material é misturado em um dia quente, as propriedades no estado fresco são diferentes de quando esse mesmo material é misturado em um dia frio.

De acordo com Myers (1992), a capacidade espumante dos incorporadores de ar depende primariamente da redução efetiva da tensão superficial da solução, das características de difusão das bolhas, da resistência da película que as envolve e de suas propriedades elásticas.

Adicionalmente, Du e Folliard (2005) afirmam que as adições nas composições cimentícias e os produtos gerados durante a hidratação do cimento afetam a formação e a estabilidade das bolhas de ar, já que a variação da concentração dos íons cálcio na fase líquida afeta diretamente as propriedades dos incorporadores de ar.

Por isso, a avaliação da cinética de incorporação de ar (em soluções com e sem eletrólitos) é um teste que, apesar de simples, pode fornecer informações sobre a característica de cada aditivo, visto que permite estudar o tempo para ação e a capacidade espumante do incorporador de ar.

\section{Considerações finais}

A utilização de incorporadores de ar nas composições cimentícias reconhecidamente traz benefícios ao setor construtivo, seja em questões ambientais ou econômicas.

Como o desempenho do revestimento aplicado é o que mais importa para o consumidor final, as pesquisas na academia ou em centros especializados são voltadas para a caracterização dos efeitos gerados após o endurecimento dos materiais. Poucas pesquisas têm ênfase na avaliação do estado fresco e um número ainda menor tenta relacionar as características no estado fresco com as propriedades no estado endurecido.

\section{Figura 17 - Efeito da temperatura na cinética de incorporação de ar na água. Em (a) é apresentado o resultado para um aditivo à base de lauril sulfato de sódio com $100 \%$ de moléculas orgânicas e em (b) com outro aditivo de mesma base molecular, porém com somente $67 \%$ de material orgânico}

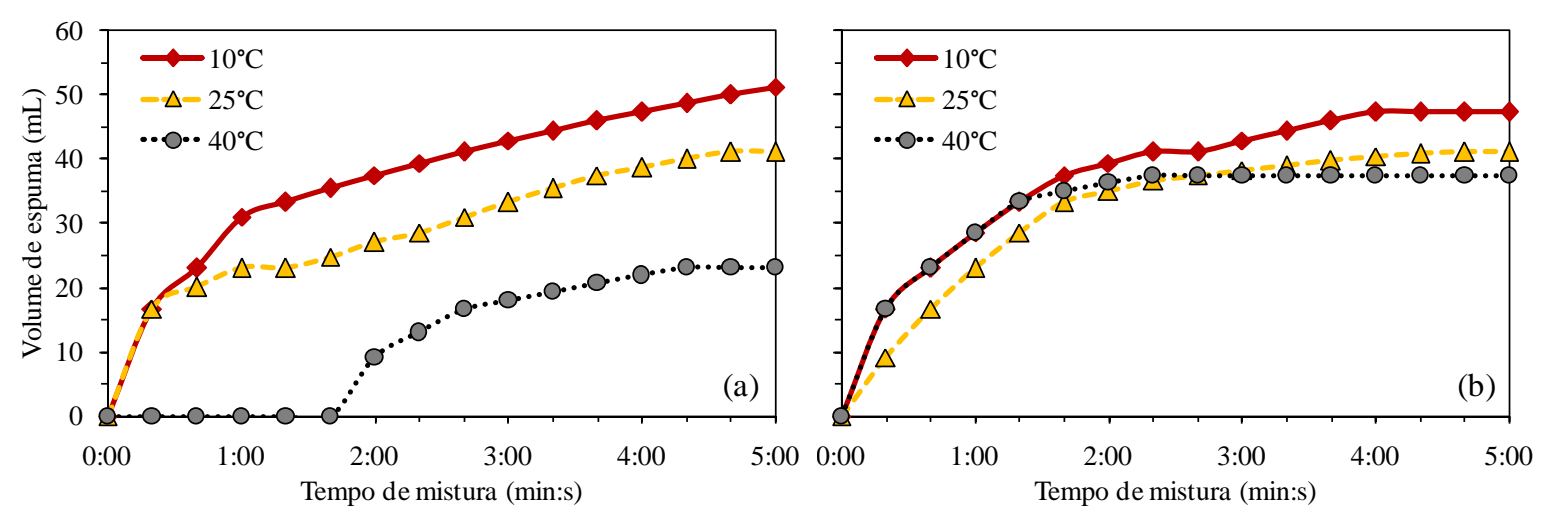


Por isso, o uso dos incorporadores de ar é apontado como um fator de complexidade operacional, pois sua presença nas composições as torna muito sensíveis a fatores extrínsecos como processamento, transporte e forma de aplicação, condição climática, etc.

Assim, mesmo com todos os benefícios que a incorporação de ar pode trazer ao setor da construção civil, muitos problemas ainda são encontrados, principalmente devido à falta de controle durante a etapa de processamento.

O que deve ficar claro é que o desenvolvimento da microestrutura porosa nas argamassas não é trivial, pois depende de muitos fatores intrínsecos das massas, como:

(a) tipo e teor de cimento;

(b) tipo e teor de incorporador de ar; e

(c) teor de água utilizado para o amassamento.

Aliado a isso, fatores extrínsecos são:

(a) energia e tempo de mistura;

(b) tipo de equipamento;

(c) temperatura da água e ambiente; e

(d) qualidade da água, etc.

Essas variáveis dificilmente são controladas durante a execução da obra e afetam diretamente a incorporação de ar, o desenvolvimento da microestrutura porosa e, consequentemente, o desempenho dos materiais cimentícios em uso.

Por isso, a avaliação separada das fases que compõem a argamassa é uma estratégia de pesquisa que, além dos efeitos, permite entender as causas da incorporação de ar nos materiais cimentícios. Isso é importante porque torna possível predizer com maior chance de acerto o que ocorrerá no revestimento a partir da utilização de ensaios simples na fase aquosa ou na pasta cimentícia, portanto antes da execução da argamassa.

\section{Referências}

\author{
ALVES, N. J. D. Avaliação dos Aditivos \\ Incorporadores de Ar em Argamassas de \\ Revestimento. Brasília, 2002. 175 f. Dissertação \\ (Mestrado em Engenharia Civil) - Escola de \\ Engenharia, Universidade de Brasília, Brasília, \\ 2002.
}

ANTUNES, R. P. N. Influência da Reologia e da Energia de Impacto na Resistência de Aderência de Revestimentos de Argamassa. 2006. 162 f. Tese (Doutorado em Engenharia Civil) - Escola Politécnica, Universidade de São Paulo, São Paulo, 2006.
ARANDIGOYEN, M.; ALVAREZ, J. I. Pore Structure and Mechanical Properties of CementLime Mortars. Cement and Concrete Research, v. 37, p. 767-775, 2007.

BENINGFIELD, N. Air Entrainment of Mortar. In: INTERNATIONAL BRICK/BLOCK MASONRY CONFERENCE, 8., Ireland, 1988. Anais... Ireland, 1988.

BRUERE, G. M. Air Entrainment in Cement and Silica Pastes. Journal of American Concrete Institute, v. 26, n. 9, p. 905-920, 1955.

CEBECI, Ö. Z. Pore Structure of Air-Entrained Hardened Cement Paste. Cement and Concrete Research, v. 11, n. 2, p. 257-265, 1981.

DU, L.; FOLLIARD, K. J. Mechanisms of Air Entrainment in Concrete. Cement and Concrete Research, v. 35, n. 8, p. 1463-1471, 2005.

FAGERLUND, G. Air-Pore Instability and Its Effect on the Concrete Properties. Nordic Concrete Research, v. 9, p. 39-52, 1990.

FERRARIS, C. F. Concrete Mixing Methods and Concrete Mixers: state of the art. Journal of Research of the National Institute of Standards and Technology, v. 106, n. 2, p. 390-399, 2001.

FORTES, M. A.; CORGHLAN, S. Simple Model of Foam Drainage. Journal of Applied Physics, v. 76, n. 7, p. 4029-4035, 1994.

HOLMBERG, K. et al. Surfactants and

Polymers in Aqueous Solution. Chichester: John Wiley \& Sons, 2002.

KUMAR, R.; BHATTACHARJEE, B. Porosity, Pore Size Distribution and in situ Strength of Concrete. Cement and Concrete Research, v. 33, n. 1, p. 155-164, 2003.

MIELENZ, R. C. et al. Origin, Evolution, and Effects of the Air Void System in Concrete: part 1: entrained air in unhardened concrete. Journal of American Concrete Institute, v. 30, n. 1, p. 95121, 1958.

MONTE, R.; UEMOTO, K. L.; SELMO, S. M. S. Qualificação de Aditivos Incorporadores de $\mathrm{Ar}$ Para Argamassas de Assentamento e Revestimento. In: SIMPÓSIO BRASILEIRO DE TECNOLOGIA DE ARGAMASSAS, 5., São Paulo, 2003. Anais... São Paulo, 2003.

MYERS, D. Surfactant Science and Technology. 2. ed. New York: VCH, 1992.

PEPER, H. The Defoaming of Synthetic Detergent Solutions By Soaps and Fatty Acids. Journal of Colloid Science, v. 13, p. 199-207, 1958.

PERRY, R. H. Perry's Chemical Engineers' Handbook. 7. ed. New York: McGraw-Hill, 1997. 
POWERS, T. C. The Air Requirement of FrostResistant concrete. Procedures Highway: Research Board, v. 29, p. 184-211, 1949.

POWERS, T. C. Void Spacing as a Basic for Producing Air-Entrained Concrete. Journal of American Concrete Institute, v. 25, n. 9, p. 741760, 1954.

POWERS, T. C. Properties of Fresh Concretes. New York: John Wiley \& Sons, 1968.

RAMACHANDRAN, V. M. Concrete Admixtures Handbook. New York: Noyes, 1984.

RIXON, R.; MAILVAGANAN, M. Chemical Admixtures for Concrete. 3. ed. London: E \& FN Spon, 1999.

ROMANO, R. C. O. Produção e Caracterização de Materiais Porosos Obtidos Pelo Método de Incorporação de Espumas. São Carlos, 2005. 171 f. Dissertação (Mestrado em Engenharia Civil) Escola de Engenharia, Universidade Federal de São Carlos, São Carlos. 2005.

ROMANO, R. C. O. et al. Efeito do Tempo de Mistura nas Propriedades de Argamassas Com Ar Incorporado. In: SIMPÓSIO BRASILEIRO DE TECNOLOGIA DE ARGAMASSAS, 7., Recife, 2007. Anais... Recife, 2007a.

ROMANO, R. C. O. et al. Impacto do Uso de Incorporador de Ar nas Propriedades Reológicas de Argamassas. In: SIMPÓSIO BRASILEIRO DE TECNOLOGIA DE ARGAMASSAS, 7., Recife, 2007. Anais... Recife, 2007b.

ROMANO, R. C. O. et al. Sensibilidade de Argamassas de Revestimento ao Procedimento de Mistura. In: SIMPÓSIO BRASILEIRO DE TECNOLOGIA DE ARGAMASSAS, 8., Curitiba, 2009. Anais... Curitiba, 2009.

ROMANO, R. C. O. et al. Caracterização Reológica de Pastas Cimentícias Com Incorporadores de Ar em Diferentes Temperaturas. In: SIMPÓSIO BRASILEIRO DE TECNOLOGIA DE ARGAMASSAS, 9., Belo Horizonte, 2011. Anais... Belo Horizonte, 2011a.

ROMANO, R. C. O. et al. Fresh and Hardened Characterization of Air-Entrained Cement Pastes. In: INTERNATIONAL CONGRESS ON THE CHEMISTRY OF CEMENT. 13., Madrid, 2011. Anais... Madrid, 2011b.
ROMANO, R. C. O. et al. Efeito da Utilização de Cales e Filitos nas Propriedades de Pastas Cimentícias. In: SIMPÓSIO BRASILEIRO DE TECNOLOGIA DE ARGAMASSAS, 9., Belo Horizonte, 2011. Anais... Belo Horizonte, 2011c.

ROMANO, R. C. O.; PILEGGI, R. G.

Temperature's Role in the Rheological Behavior of Cementitious Pastes Prepared With Air-Entraining Admixtures. Applied Rheology, v. 22, p. 24333243341, 2012.

ROMANO, R. C. O. Incorporação de Ar em Materiais Cimentícios Aplicados em Construção Civil. 2013. 197 f. Tese (Doutorado em Engenharia Civil) - Escola Politécnica, Universidade de São Paulo, São Paulo, 2013.

ROMANO, R. C. O.; TORRES, D. R.; PILEGGI, D. R. Impact of Aggregate Grading and AirEntrainment on the Properties of Fresh and Hardened Mortars. Construction and Building Materials, v. 82, p. 219-226, 2015.

SALAGER, J. L. El Mundo de los Surfactantes. Cuaderno FIRP, S311-A, p. 3-4, 1992.

SALAGER, J. L. Surfactantes em Solucion Acuosa. Cuaderno FIRP, S201A, p. 1-28, 1993.

SALAGER, J. L. Surfactantes: typos y usos. Cuaderno FIRP, S300A, p. 1-54, 2002.

SALAGER, J. L.; FERNANDES, A. Surfactantes Aniónicos. Cuaderno FIRP, S302PP, p. 1-30, 2004.

SELLEVOLD, E. J. Mercury Porosimetry of Hardened Cement Paste Cured or Stored at $97^{\circ} \mathrm{C}$. Cement and Concrete Research, v. 4, p. 399404, 1974.

VYDRA, V. et al. Influence of Temperature on Induction Period and on Ultimate Porosity of Hardening Cement Paste. Construction and Building Materials, v. 21, p. 1262-1266, 2007.

WHITING, D. A.; NAGI, M. A. Manual on Control of Air Content in Concrete. 2. ed. Illinois: Portland Cement Association, 1998.

ZHANG, D. S. Air Entrainment in Fresh Concrete With PFA. Cement and Concrete Composites, v. 18, n. 6, p. 409-416, 1996.

ZHANG, H. et al. Mechanism for Defoaming by Oils and Calcium Soap in Aqueous Systems.

Journal of Colloid and Interface Science, v. 263, p. 633-644, 2003.

ZHANG, H. et al. Defoaming Effect of Calcium Soap. Journal of Colloid and Interface Science, v. 279, p. 539-547, 2004. 


\section{Roberto Cesar de Oliveira Romano}

Escola Politécnica | Universidade de São Paulo | Av. Professor Almeida Prado, Trav. 2, 83, Cidade Universitária | São Paulo - SP - Brasil | CEP 05508-900 | Tel.: (11) 3091-5382 | E-mail: rcorjau@gmail.com

\section{Maria Alba Cincotto}

Departamento de Engenharia de Construção Civil, Escola Politécnica | Universidade de São Paulo | Tel.: (11) $3091-5792$ |

E-mail: cincotto@usp.br

\section{Rafael Giuliano Pileggi}

Departamento de Engenharia de Construção Civil, Escola Politécnica | Universidade de São Paulo | Tel.: (11) 3091-5442 |

E-mail: rafael.pileggi@usp.br

\section{Revista Ambiente Construído}

Associação Nacional de Tecnologia do Ambiente Construído

Av. Osvaldo Aranha, 99 - 3o andar, Centro

Porto Alegre - RS - Brasil

CEP $90035-190$

Telefone: +55 (51) 3308-4084

Fax: +55 (51) 3308-4054

www. seer. ufrgs. br/ ambienteconstruido

E-mail: ambienteconstruido@ufrgs.br

(c) (i)

This is an open-access article distributed under the terms of the Creative Commons Attribution License. 